\title{
O teATRO ITALIANO GROTESCO DO PRIMERRO NOVECENTO
}

\author{
CAROLINA MASSI ALBANESE *
}

\subsection{Questōes e motivos}

A fórmula - teatro grotesco - criada por Chia:elli e pela sua peça A Máscara e o vulio não concerne a um movimento definido nem tão pouco organizado: tem, todavia, valor lengínquo no tempo, na história do poesia e da arte dramática italiana, e evoca as razōes mais remotas e presentes do nosso teatro, desde a antiga expressão horaciana do Italicum acełum até o cômico dramático moderno.

Torna-se útil apresentar, embora sumariamente as questöes $\mathrm{e}$ os motivos que impeliram o desabrocho do teatro italiano grotesco do primeiro novecentos.

O teatro italiano entre os séculos XIX e XX poderia ser classificado segundo ttês linhas que marcam o caminho os influxos, as aberturas:

O teatro regional.

A comédia burguesa.

A comédia antiburguesa.

O teatro regional e a comédia burguesa apresentavam um panorama mais ou menos homogêneo, tendo como prog:ama básico:

a) Fornecer uma imitação estritamente fotográfica da realidade;

b) Não permitir a intervenção do autor.

"Categorias divididas por altas e tétricas muralhas, abismos sem

* Carolina Massi Albancso é diplamada na lib́lia, onde nasceu, em Língus c Liserstura Italiana o Livre Docente pela Universidade Federal do Paraná em $1974 \mathrm{ccm}$ a tese II significato dol Gatlopardo. Publicou vários artigos cm revistas cspzcia!izedas e, atuslmonto, leciona, na condiçäo de Auxlliar de Ensino Lingua Italiana na Universideda fedaral da Paraná. 
fundo, entre as realidades materiais e as ideais, entre a verdade e o sonho, princípios e caracteres constritivos como grilhōes, relaçōes entre causas e efeitos calculados nas balanças dos farmacêuticos (...) estas eram as leis que regiam o teatro"', diz Luigi Chiarelli, indignado e amargurado.

- Século $X X$, logo no início, revela sintomas de inquietação. Surgem reações à tradição primeiramente nebulosas, em seguida cada vez mais claras e determinadas. O mundo, que até então se apresentara sólido e em contínuo melhoramento, os ideais e as estruturas da sociedade burguesa, vinculados ao credo positivista, são sacudidos pela dúvida e pela decepção, as quais afugentam as ilusões ingênuas em cada campo, não excluindo a estética. Uma era estava morrendo e outra principiava a nascer. Uma crise profunda de especulação provoca a mudança da visão filosófica e artística e, paralelamente, a crise social e individual. $O$ indivíduo sente que vacila: o protesto torna-se sua bandeira.

A tentativa de Gabriele D'Annunzio de reconduzir ao palco "l'esclusa la poesia", não consegue dizer uma palavra verdadeiramente nova.

E neste ponto que intervêm os futuristas:

- 1905, em Paris, com a tragédia satírica "Le Roi Bombance";

- 1903, com "Manifesto del Teatro di varietà", publicado na revista Lacerba. Afirma-se resolutamente: "Temos um profundo nojo do teatro contemporâneo (versos, prosa e música)“².

Na veste de incansável condutora e com a atitude de revolta, a vanguarda anuncia a criação de um teatro sintético, atécnico dinâmico e alógico. É a condenação em bloco da comédia burguesa. A iniciativa vanguardeira supera o texto, para ocupar campos de realização; cenografia, indumentária, direçāo...

Apesar dos futuristas não conseguirem nesta obra fecunda de abertura o êxito que obtiveram em outros campos, têm eles o merecimento indiscutivel de revolver as águas.

A verdadeira ação de ruptura será justamente levada a efeito pelos autores do grotesco. Chiarelli afirma: "Queremos ser nós mesmos, dizer a palavra de nosso tempo e não repetir rançosas roman-

I ChIAREllI, Luigi. II vero volto della-Merchera a il volto. II Dramma, Milano (246): 50, mar. 1957.

2 PAVOLINI, Carlo. Fut urismo. In: ENCICLOPEDIA dello Spettacolo. Roma, 1958. v. 4, p. 785. 
ças, que não conseguem emocionar nem mesmo as velhas solteironas"3. Antonelli também comenta: "Eu respeito muito A Dama das Camélias e A Ceias das Befas. Gostaria de tê-las escrito muitos anos atrás... Mas hoje estão ultrapassadas"4.

Das afirmaçōes de Chiarelli e Antonelli podemos deduzir que não se trata tanto de uma condenação da produção passada, quanto do reconhecimento de que aquela produção não está mais adequada à situação do tempo. A nova tomada de posição de protesto, de fato põe abaixo a última tradição teatral do Século XIX sem muito barulho. Não há estrondosas invenções: o caminho preferido é o da sátira e aplica-se a idéia dos clássicos temas burgueses (o adultério, o dinheiro, etc.). Entrementes, se a primeira fase é tradicional, a evolução progressiva dos personagens e a conclusão demonstram claramente que aqueles ingredientes tradicionais serviram para combater o naturalismo, isto é, são usados contra a comédia buiguesa.

Por outro lado, o próprio Chiarelli define assim sua peça:

"A Máscara e o Vulto não é senão uma espécie de marcha contra o drama romântico burguês, feita com finalidade revolucionária, para poder em seguida colocar as novas posiçōes do drama de acordo com a sensibilidade de nosso tempo, as aspiraçōes de nosso espírito (...) o grotesco é uma arma"s.

\subsection{A poética do Grotesco.}

Em 29 de maio de 1916, no Teatro Argentina de Roma, é representada A Máscara e o Vulto, que o autor Luigi Chiarelli define como "um grotesco". Nos anos seguintes, vêm à ribalta Marionetes, que paixăol de Rosso di San Secondo, A Ave do Paraíso de Cavacchioli e $O$ homem que encontrou a si mesmo de Antonelli. Trata-se de um cômico que não se sabe se provoca o riso ou o choro ou ambos, em suma, é aquela combinação que chamamos "grotesco" e que se apresenta com certos estrambóticos paradoxos.

Fala-se de uma nova escola teatral italiana, à qual é dado o nome da feliz expressão adotada por Chiarelli; "grotesco". Contudo é possivel falar em verdadeira escola? Os comediógrafos em questão rejeitam esta classificação, afirmando cada um sua própria independência. Diz Chíarelli; "Fala-se muito na escola do grotesco, na qual vêm enfeixadas as obras mais diversas $\epsilon$ com uma

3 CHIARELLI, Luigi. Anticipo alle mio memoric. II Dramma, Milano (53), 35, oll. 1948.

4 CHIARELli, Luigl. La compagnía del teatro moderno. Comoedia, Milano, p. 44. 25 ago. 1920.

5 CHIARELLI, II vero volto ..., p. 60. 
apreciação sempre sumária e inexata... Uma escola propriamente definida do grotesco não existe"6.

Após uma indagação mais aprofundada, a poética de cada autor apresenta caracteres distintos; há, todavia, um elemento que pe:mite reunir esta produção: por caminhos diferentes é executada a mesma ação de ruptura com a tiadição verista. O ponto de partida desta ação polêmica é a demolição do suporte da conzepção teatral burguesa; a arte encarada como reprodução da realidade. A reprodução da realidade pressupõe fé na iealidade enquanto que a crise do pensamento da primeira metade do Século $X X$ envolve a consistência da realidade. $O$ quesito gnoseológico se contrapõe ao quesito moral típico da produção do Século XIX. A realidade, para Chiarelli, é "uma atitude de nosso pensamento. Uma coisa pensada é uma verdade (...), não há nada que seja verdadeiro, nada que seja falso"?.

Rosso di San Secondo postula a existência de uma dupla realidade na vida:

"Se a vida fosse uma só coisa, se tivesse um único aspecto, a humanidade não sentiria a necessidade da arte, pois seria completamente supérfluo reproduzir alguma coisa que todos indistintament? enxergam, que todos sentem. algo que se oferece por si de um determinado modo, sem a particular revelaçāo do poeta"в. relli;

Estas posições e, principalmente, a afirmação seguinte de Chia-

"Na arte são somente verdadeiras aquelas verdades que encontram correspondência com as nossas formas mentais. $O$ verdadeiro e o falso, o verossímil e o inverossimil nāo existem para a arte, a não ser enquanto estes têm fundamento em nossas idéias e não porque concordam com as realidades habituais", conclamam explicitamente o conceito de autonomia do teatro da realidade. Autonomia do teatro, porém. não significa abstração da vida; aliás, o teatro torna-se um meio para conhecê-la.

Diz Antonelli:

"Qual é a importânca de, no fim do terceiro ato, ter eu contado ao público que fulana traiu o marido, que mais tarde nascera

8 CHIARELLI, II vero volto ..., p. 67.

7 CHIARELl, Luigi. Fucchi d'artificio. Comoedia, Milano, p. 22. 1.0 mar. 1923

a ROSSO DI SAN SECONDO, Pier Muris. L'avventura terrestze. In: FERRANTE, Luigi. Teatro. Bologna, Capelli, 1962. p. 84.

9 CHIARELLI, Fuochi..., p. 15 
um filho e sobreveio a reconciliação? Ainda que o público saia satisfeito, contei-lhe uma bem misera história", $\circ$.

A temática agora muda; protagonista da comédia não é mais a vida cotidiana, e sim o momento da insegurança que pōe em dúvida tanto a validade do mundo externo, quanto a compacidade da própria personalidade.

Na comédia burguesa, posta a situação, costumeiramente centrada no adultério ou no dinheiro. o evento enveredava por binários preestabelecidos até a demonstração da tese final, que rebatia a necessidade do sistema de vida e de regras existente. No teatro grotesco, ao invés, o personagem reflete a crise do homem como ele é nas formas da convivência social e como ele se sente no intimo de sua alma: o jogo amargo, a alteração paradoxal do perfil humano e as laceraçōes internas, os disfarces da personalidade humana sob a violência das convençōes e dos costumes. É revalorizado o momento crítico na arte e na vida, a presença na segunda, necessária para infringir os limites fixados pelas regras preconstituidas. Eis que nasce aquele misto entre vida-teatro, espetáculosimulação, explorado por Pirandello e outros. A.firma Chiarelli: "Quero que a ação teatral seja mais vasta que o seu arco cênico. Hei de divertir o público e enquanto o divirto procuro fazê-lo pen. sar"is.

Não é teatro de evasão, portanto, mas teatro que forneça algo ao espectador, que the dirija uma mensagem que o sacuda e obrigue a meditar. Esta é realmente a finalidade que os nossos autores querem alcançar: apresentando suas peças, recusam-se a arrastar e comover os espectadores e hipnotizá-los, pois propõem-se, por um lado, apresentar-Ihes problemas que os envolvem, e por outro, despertar neles uma faculdade crítica que os leve a recusar ou, pelo menos, a julgar o mundo em que vivem e o espetáculo ao qual ossistem.

Um dos expedientes mais eficazes pa:a promover esta ação critica é o personagem, coro ou eu-épico, como o chama Gigi Li$v^{1}{ }^{12}$, que comenta o drama desvendando as ações e os sentimentos, para descobrir o verdadeiro significado ou a ausência de significado. A. função desse personagem é, portanto, eminentemente critica e desagregadora.

Em Chiarelli, as contradições humanas, o ser e não ser, a dor,

10 ANTONELLI, Luigi. Lo serittore si confessa. Roma, Scisscia, 1943 p. 270

11 CHIARELLI, II vero volto ..., p. 51.

12 LIVIO, Gigi. Toatro del Novecento Milano, Mondadori, 1965 p. 81. 
- ricículo mecanizam-se, tornam-se fatos, acidentes, isto é, exterioridade. A Máscara e o Vulto é a paródia da coerência e a grotesca revelação de uma frafura entre os preceitos de uma inexistente moralidade e o comportamento moral.

Em Rosso di San Secondo, o contraste entre o ser e o querer ser, entre aquilo que é subjetivo (o individuo) e aquilo que é objetivo (a situaçāo) encontra uma soluçāo em uma invenção necessária, em que o dado sensorial quase se dissolve, para assumir um valor lírico denso de reflexos psicofísicos.

Em Bontempelli, o grotesco nasce com a restituição do fato à sua "banalidade".

Em Cavacchioli, o dissídio sinceridade-simulação é representado paradoxalmente sobretudo na piovocação teatral Aquele que a ti se assemelha. Observamos a descrição que o autor faz de seus personagens:

"Leonardo. Quarenta anos, calvo, bigodudo, volumosa barriga: representa o senso estático, fanfarrāo, medroso da vida.

Gabriele. Longo, definhado, espectral,, lamentoso, é o ideal sempre recalcado.

Gabriella. Jovem, cabelos verdes, volúvel, carnal, râncida no sentimento, enconira o idolo só no sentimento de sua humanidade.

O Mecânico. E o praticismo inexorável, maquinal da existência. Tem duas rodas no lugar dos olhos. Parece todo um maquinismo de alavancas, de pequenas engrenagens, em vez de homem"13.

O processo de desagregação do caráter, no grotesco, toca pontos extremos. As figuras de Rosso di San Secondo não apresentam evoluçōes, e o único caminho de saida é o suicidio (Marionetes, que paixāo!) ou o homicidio (O hóspede desejado, $\mathbf{O}$ delírio do taberneiro).

Cavacchioli quase sempre faz uso de personagens simbólicos. Antonelli leva ao palco animais falantes como em $\mathbf{A}$ ilha dos macacos, ou personagens desdobrados, um na frente do outro, como em $O$ homem que encontrou a si mesmo.

Que ideais podem ser ainda considerados válidos? Recusando as estruturas sociais sentidas como simulaçōes, que violentam

13 CavacChiol, Enrico. Quello che I'assomiglia. Milano, Mondadori, 1922 p. 2. 
a libeidade do indivíduo, o único elemento que pode ser considerado positivo é o instinto. Para Antonelli, o bem perdido é o gaúdio do instinto; no Prólogo a A ilha dos macacos ele diz:

"Senhores! A amargura desta fábula que estais prontos para ouvir obrigou-me a vos dirigir algumas palavras antes que eu me torne macaco. São minhas últimas palavras, pelo menos, por esta noite, que eu pronunciarei como homem: e não são alegres, pois eu me tornarei macaco para me colocar contra os homens... Para esperar ainda alguma coisas dos homens e para crer em seu futuro, é preciso grifar por tudo aquilo que eles destruíam e se preparam para destruir. Todo o bem que eles possuiam está no gaúdio de seu instinto! Se eles não o tivessem embrutecido, possuiriam ainda hoje a felicidade de existir [...] Existem criaturas pequenissimas que navegam nos espaços e possuem todos os privilégios da terra e do céu. O homem tinha todos aqueles privilégios e um a ma:s, que the provinha da consciência de possuí-los. Pois bem, ele os destruiu! e hoje está reduzido a invejar os animais, quando está cansado de invejar o próximo. [...] Eh! Há um desespero nisto, que talvez ninguém imagina qual seja"14.

Para Rosso di San Secondo, o instinto e a paixão comprecndem as sensações vitais que se afirmam violentamente contra as estruturas sociais e se identificam em uma desesperada exigência de liberdade. O mesmo serve como critério de composição da obra de arte. Chiarelli observa que da comédia burguesa eram banidos: "o capricho fechado como uma magnífica ave do paraíso na estreita gaiola das convençōas; o caso, este fresco e vivo manancial que jorra de repente, sufocado sob as exigências da ciência psicológica e social"15, e reivindica a presença na obra poética de um elemento irracional: "o grande desconhecido que vive dentro de nós, rico de seus maravilhosos segredos, que nos atrai e nos guia com violência cega para executar a obra de arte"lob.

Exige-se, portanto, uma criação livre de regras pré-fixadas, quase como desforra à coação contínua da vida social.

Infelizmente, os autores do grotesco chegaram ao excesso opos10, ou seja, à falta de um programa. Este é o ponto dolorido das poéticas do grotesco, sua validade exclusivamente polêmica, mas ao mesmo tempo é também sua força positiva, pois o teatro grotesco alcança a sua finalidade: desmantelar a tradição, de moneira que

14 ANTONELLI, Luigi. L'isola dollo seimmio. Roma, Scioscia, 1943. p. 2.

15 CHIARELLI, II vero volto..., p. 49

16 lbid., p. 49. 
o palco não hospede mais uma imitação da realidade que pretende ser objetiva, mas sim denuncie explicitamente as simulaçōes da vida - aquelas da arte. O momento crítico, de resto, adquire em toda a arte do Século $X X$ uma importância cada vez mais marcante ao lado do momento intuitivo.

\subsection{A Máscara e o vulto}

Precisamos justificar o porquê da escolha analítica de A Máscara e o Vurito, que não é certamente uma das melhores peças do teatro grotesco. É que o teatro grotesco deriva sua denominação de A Máscara e o vuito de Luigi Chiarelli.

A Máscara e o vulto nasce de uma posição crítica, além de filosófica e polêmica. Polêmica com respeito à convivência conjugal e a todas as consequéncias sociais. Filosófica, pois abo:da com grande clareza e vivo senso do humano os problemas da personalidade. Crítica, porque subverte todas as regras da velha técnica teatral, desrespeitando os gastos esquemas imperantes sobre os quais se moldava a literatura dramática burguesa.

A peça, qualificada pelo autor de "grotesco em três atos", visa evidenciar a deformação originada em nós pelo contraste entre aquilo que queremos parecer e aquilo que de fato somos. O propósito desta peça é, portanto, a acentuação do desprestígio em que acaba se encontrando o individuo, diante de uma sociedade que mortifica a vida e ofende a íntima moralidade. A Máscara e o vulto conseguiu um enorme sucesso, que o autor assim interpreta:

"Se A Máscara e o Vulto foi definida como obra de libertação e obteve unânimes aplausos, e não só na Itália, significa que nela foram reconhecidos elementos que respondiam a uma necessidade por todas sentida; isto é, significa que o velho drama estava morto 117 .

O primeiro grotesco gira em torno do medo da derisão e coloca em cena o costumeiro triângulo e um corrompido ambiente burguês. A peça parte de premissas normais e se complica, em seguida, com casos extravagantes. dos quais são extraídas "trágicas" conclusões. Chiarelli vitaliza velhos motivos com um novo fermento de idéias. Dentro de uma moldura cênica tradicional, a renovação é obtida na estrutura interna do personagem.

Durante uma recepção em sua vila, perto de um lago, Paolo Grazia declara que, se fosse traido pela mulher, a mataria, pois

$17-$ CHIARELLI, II vero volio ..., p. 51 
"um marido que perdoa é ridículo" e "para um tal marido não resta senão o suicídio depois"18.

Na mesma noite ele descobre que a esposa Savina o trai. Sua verdadeira intenção seria perdoar; mas agora essa soluçāo diante dos amigos e da sociedade lhe é vedada, mais ainda depois de suas afirmaçōes. Paolo obriga então a esposa a esconder-se no exterior sob falso nome e diz ter jogado a adúltera no lago. Absolvido após ter sido defendido calorosamente pelo próprio amante da csposa. que é advogado, Paolo volta a sua casa e é recebido como um triunfador. Por isso é tomado por um sentimento de revolta: "Não há nada de sério neste mundo? Torna-se ridículo até o drama mais angustioso!?... E é por causa dessa gente que eu... Palhaços?!"

E a lógica do ridículo, Basta pouco: obrigar alguém a manter a palavra, a ser coerente! Paulo deverá matar a esposa que o engana, mas não saberá matar. Fingirá então, e, graças a uma vingança somente inventada, a um uxoricídio não realidado, mas em que todos acreditam, ele terá apoio e renome. A situação to:na-se mais paradoxal quando o amante da esposa é obrigado a acusá-la vilmente no tribunal. Será feita justiça, à maneira moralmente grotesca do comum engano. A esposa arrependida e apaixonada volta, e Paulo reconcilia-se com ela, correndo o risco de ser condenado por simulação de crime: "matei-a e me absolvem... não a matei e me mandam para a prisāo":o . O casal escapará da condenação, fugindo e dando as costas a uma sociedade mais disposta a aceitar a hipocrisia do que a verdade.

Teatro de efeito, eis um atributo usado para o grotesco. O efeito é uma temática constante em nossos autores; não será, porém, um cfeito macabro (embora o encontremos em algumas peças grotescas), e sim progressivo. Pensamos na cena do cadáver encontrado no lago de Como, na qual todos, inclusive o marido, reconhecem Savina; ou naquela outra arquitetada por Savina, que vai ao suposto funeral e avança no meio da multidão, vestida de luto, com o rosio escondido por um espesso véu, impenetrável.

O tema da despersonalização se acentua no desenrolar do enredo; o tema da solidão também: uma solidão em que o ser se encontra, imposta, não desejada.

Mais ainda do que a aventura em si, interessam as digressões do personagem Cirillo, coro ou eu-épico, que expõe e discute os

is CHIARELLI, Luigi. La Maschera e II Volto. Firenze, Libreria dol Teatro, 1931. p. 14.

19 lbid., p. 32

20 lbid., p. 66 
mitos burgueses, infiltrando-lhes o estro grotesco, um fio sutil de ironia intelectual e ofertando-os ao público, esvaziados e inertes.

Apesar do desenvolvimento da peça ser linear, de uma simplicidade e, diríamos, de um mecanismo infantil, isto não impede que seja completamente abstrata a concepçāo d odrama, o eixo da engrenagem: o drama da limitaçāo da pessoa humana por obra dos "outros" e da esquematização de sua vitalidade fixada paradoxalmente em "caras" convencionais. Há uma sutileza na ironia com que a vitima se subtrai à violência da sociedade, excogitando formas aparentes para esconder seu vulto de uma situașāo difícil e "jogar" assim a sociedade: uma longa sátira de compromissos aos quais Paulo deve sotopor-se.

O significado moral da peça é de um pessimismo profundo. 0 homem, portanto, não consiste a não ser por um impulso reflexo, é um empastamento de reaçōes, o que os outros ou as situaçōes o tornam. E privado, pois, de uma certa autonomia própria.

No entanto, ao contrário da maioria das peças grotescas, nesta há uma saída: Paolo consegue de certa forma resgatar sua liberdade.

Em A Máscara e o Vulto, Chiarelli segue a tese dos autores do grotesco; a reivindicação do instinto, que se identifica com um anseio de liberdade. O drama nasce da luta entre as convençōes sob as quais a vida se torna máscara e se esconde, e a espontaneidade do instinto vital que se reafirma contra elas.

\section{RESUMO}

Em 29 de maio de 1916 é representada A Máscara o Vulto, que o autor Luigi Chiaielli define como "um grotesco". Nos anos seguintes, vêm à ribalta peças de Rosso di San Secondo, Anfone:li, etc. Fala'se de uma nova escola teatral italiana a qual é dado o nome da feliz expressão adolada por Chiarelli: "grotesco". Os comodiógrafos em questão rejeifam esta classificação, afirmando cada um sua própria independència. A poética de cada autor, de fato, apresenta carecteres distintos; há, todavia, um elemento que permite reunir esta produção: por caminhos diferentes $b$ executoda a mesma açāo de ruptura com a tradiçāo verista. A temática agora muda; protagonista do comédia nāo é mais a vida cotidiana, e sim a momento da insegur rança que pōe em dúvida tanto a validade do mundo externo, quanto a compacidade da piópria personalidade.

Um dos expedientes mais eficazes para promover esta ação critics $f$ o persona* gem, coro ou euépico, que comenta o drama desvendando as açōes e os sentimentos, para descobrir o verdadeiro significado ou a ausência de significado. 


\section{RIASSUNTO}

II 29 maggio di 1916 viene rappresentato La Maschera e il Volto che l'autore Lulgi Chiarelli definisce "un grottesco".

Negli anni successivi vengono alla ribalta opere di Rosso di San Secondo, Antonelli ece. Si parla di una nuova scuola teatrale italiana a eui viene dato il nome dalla fortunata formula adottata da Chiarelli: "grottesco" I commediografi in questione rifiutano questa classificazione offermando ognuno la propria indipendenza. Ad una indagine approfondita le peetiche dei singoli auteri p resentano caratteri distínti, c's pord un elemento che permette di riunire questa produzione: per vie diverse à operata la stessa azione di rottura con la tradizione verista.

La tematica adesso cambia: protagonista della commedia non è più la vita quo* tidiana, ma si il momento dell'insicurezza che mette in dubbio tanto la validità del mondo esterno quanto la compattezza della propria personslità. Uno degli espedienti piú consapevoli e riflessi per promuove:e questa azione crítica è il personaggio, coro - io epico, che commenta il dramma scandagliando i retroscena delle azioni e dej sentimenti per svelarne il vero significato.

Rifintando le struture sociali sentite come finzioni che violentano la libertó dellindividuo e il sistema di valo:i borghesi, svuotato di senso, l'unico elemento che può considerarsi positvo è l'istinto che viene ad identificarsi con una esasperata esigenza di liberta.

\section{REFERENCIAS BIBLIOGRAFICAS}

ANTONELLI, Luigi. L'isola del'o scimmie. Roma, Sciascia, 1943. 112 p. . Lo scrittore si confassa. Roma, Sciascia, 1943, 290 p.

CAVACCHIOLO, Enrico. Quel!o cho t'assomiglia. Milano, Mondadori, 1922, 96 p.

CHIARELLI, Luigi. Anticipo alle mie memorie. Il Dramma, Milano, (53) ott. 1948.

-_-_- Fuochi d'artifício. Comoedia, Milano, $1.0 \mathrm{mar} .1923$.

_-____. La Maschora e il Volto Firenze, Libreria del Testro, 1931. 70. p. - - I _ I vero volto della Maschera e il Volto. II Dramma, Milano, (246) mar. 1957.

LIVIO, Gigi. Teatro dol Novoconto Milano, Mondadori, 1965. 190 p.

PAVOLINI, Carlo. Futurismo. In: ENCICLOPEDIA dello Spelfacolo. Roma, 1958. v. IV.

ROSSO DI SAN SECONDO, Piar Maria L'ovventuro terrestre. In: FERRANTE, Luigi. Teatro. Bologna, Cappelli, 1962. $181 \mathrm{p}$. 